\author{
Delia BĂLĂCIAN, PhD Candidate \\ E-mail: delia.balacian@gmail.com \\ Economic Cybernetics and Statistics Doctoral School \\ The Bucharest University of Economic Studies \\ Professor Emil SCARLAT, PhD \\ E-mail: emilscarlat@ymail.com \\ Department of Economic Informatics and Cybernetics \\ The Bucharest University of Economic Studies
}

\title{
THE CYBERNETIC SYSTEM OF THE GLOBAL ECONOMY WITH INFLUENCES OF CLIMATE CHANGE ON THE EVOLUTION OF IT
}

Abstract. The present paper proposes a general model of the cybernetic system of the global economy which has direct and indirectly relations with the complex system of climate change. The main objective of the paper is to illustrate some of the interesting relations between two systems through stock - flow diagrams, developed in Stella 9.0. The study of these relationships allows decisions makers to gain a perspective on the influences of climate change on the evolution of economy and the other way around. Year by year, the state of the climate is changing and its effects are becoming more and more likely. The globalization phenomenon has accelerated the peace of change and societies worldwide struggle to adapt in order to survive. Additionally, it must be taken into account the fact that Earth's resources are limited and have a strategic value attached to. Therefore, the difficulty to predict future possible outcomes of policies and behaviors is raising.

Keywords: Climate Change, Economic Cybernetics, System Modelling.

\section{JEL Classification: P18, P28, Q51}

\section{Introduction}

Over time, human actions have led the planet's transition to a new geological era: Anthropogenesis. This era, characterized by great complexity, uncertainty and instability, is primarily driven by the impact of human activity, which threatens the economies, societies and even the survival of our species, challenging scientists, policy makers and environmental management activists in order to find those trends of future development that lead to the greatest possible level of sustainability.

Today, the harmful influence of human activities, especially those from the industrial sector, on the current state of the climate through the greenhouse gases

DOI: 10.24818/18423264/55.1.21.02 
produced is indisputable: the quantity accumulated from the period of the Industrial Revolution to the present, about the last 150 years, is characterized by a faster growth rate than the quantity accumulated since the Agricultural Revolution to date, meaning about the last 12,000 years. Also, over the past 150 years, temperature, humidity and sea levels have increased, while snow and ice levels have decreased (Tol, 2019).

The increase in the concentration of greenhouse gases in the atmosphere, as well as the amount of solar radiation reflected back into space, is intensified due to changes in the land surface, caused by commercial exploitation of the land, deforestation, natural fires or the use of chemical fertilizers. Clearly, these two are key factors leading to changes in the dynamics of the global climate in the contemporary age (Rosa E. A., 2015). Note that one of the main factors, land changes, is controlled and influenced by human decisions. Human activities are therefore primarily responsible for altering the land surface, implicitly for increasing the concentration of greenhouse gases.

In this dynamic context, but also in the spirit of promoting sustainable communities, it must be taken into account the difference between developed and developing countries, with the aim of developing the latter in a common beneficial direction. Moreover, developed countries should demonstrate a moral duty because their economic development is probably a cause of the deterioration of the environment and the effects of climate change that we have experienced in recent decades. Thus, developed countries could provide financial, technological and operational support to developing countries for the direct integration of best practices. This topic leads further to the perspective on the global economy, characterized by more complex processes and interactions and which are taking place at a faster pace.

The phenomenon of globalization is characterized by investment (foreign direct investment, short-term capital, investment agreements, etc.) and trade, which influence the economy of each country involved by increasing or diminishing its development. However, some aspects of society such as capital flows, people and the baggage of knowledge accumulated by each nation benefited from a liberalization that generated negative effects which were not initially expected. The promoters of globalization have viewed this process of opening up global capital markets as one that will redirect capital flows to the most productive points. Unfortunately, the liberalization of capital does not mean effective management of it, hence it has not been achieved a more efficient production or a higher growth rate. On the contrary, this liberalization can lead to greater instability and inequality.

Globally, the effects on the climate are influenced by the consumption habits of the population, which are increasingly demanding for production, supply and delivery chains, influencing economic growth. Beside consumer's preferences, the inequality caused by globalization must be considered: some economic operators benefit, while others rather lose resources. These gains and losses are

DOI: $10.24818 / 18423264 / 55.1 .21 .02$ 
The Cybernetic System of the Global Economy with Influences of Climate Change on the Evolution of IT

found both on the capital market and in the case of other categories of resources, such as labor, raw materials or the accumulated knowledge.

Therefore, a complex system resulting from the interaction between the climate system and the global economy system, each influenced by the phenomenon of globalization, captures numerous interdependencies, the effects of which on the general state of the system are difficult to predict. At this point, it is justified to use a language to model complex systems, such as Stella.

\section{References for Model Construction}

In this section we will present the scientific milestones that helped to build the overall model of the global economy, with influences of climate change on its evolution. In the process of explaining the links between the economic aspects of societies and the effects on climate change, but also vice versa, various models have been developed. Mainly, they aim to predict economic growth, considering the factors that can influence it, including population growth, technological innovation, migration, environmental pollution and others.

The model proposed in this paper takes into account the tendency of companies to adopt sustainable initiatives in the future and the possibility of implementing stricter policies in environmental protection. Today, what we mean by "green" growth is defined as the growth that is effective in the use of its natural resources, clean in the sense that it minimizes pollution and environmental impact, and adds resilience in the treatment of natural hazards and in the assumption of the role in the management of the environment and natural capital in order to prevent physical disasters.

In the following paragraphs, four scientific benchmarks will be presented briefly. They address the links between the economy and the climate in different ways, namely the Environmental Kuznets curve (Stern, 2004), the complex adaptive system of the national economy (Scarlat \& Chiriţă, 2003), a general diagram for models that integrate the economic system and the climate one that it is used to generate scenarios for estimating the future amount of greenhouse gases (van Kooten, 2013) and lastly the DICE model, developed by Nordhaus (Wang, 2017).

The first topic addresses the Kuznets curve, which defines the link between income inequality and economic growth and which later evolved into the Environmental Kuznets Curve (EKC), based on the studies conducted by Grossman and Krueger to determine the environmental impact of the NAFTA (North American Free Trade Agreement). The EKC is essentially based on a hypothesis of the relationship between per capita income and various indicators representative of environmental degradation, such as those related to pollution or the quality of air, water and soil. In other words, it is necessary for society to reach a certain level of well-being and overcome it, so that mitigating the effects of

DOI: $10.24818 / 18423264 / 55.1 .21 .02$ 
climate change and protecting the environment become priorities for the majority of the population, according to Beckerman (1992) in (Beyene \& Kotosz, 2019).

Perhaps the most attractive aspect of this possible relationship is the chance to achieve a desirable level of sustainability without significantly changing the ways in which economic activities are currently carried out. Although Kuznets' merit is generally recognized for developing a theory on the environment economic development relationship, this link has been widely criticized. In 2004, Stern presented an insight into the Kuznets environmental curve that incorporates views that support this relationship, but especially arguments that challenge it. The criticisms relate to both the theoretical and the econometric dimensions.

Moreover, the link between economic growth and environmental degradation is not only direct, but also indirect, through trade. Pollution is another factor that can have an impact on the development of the economy, even if the relationship is usually viewed in reverse. These interdependencies need to be carefully considered, especially from a dynamic perspective.

The second scientific landmark is the complex adaptive system of the national economy. It comprises six interdependent subsystems, which are also characterized by other actors, variables, relationships and feedback loops: the household system, the business sector, the government sector (public), the external sector, the financial system and the Central Bank's reserves (Scarlat \& Chiriţă, 2003).

If the national economy describes the flows and behavior of actors within a country, the global economy system targets the entire population of the Earth and shifts attention from macroeconomic decisions and regulations to international initiatives between country representatives. Moreover, there are private economic operators acting globally, determining the trend of the whole economy. Such agents are investment companies that focus their capital on certain visions of how human society should develop in the long term. Thus, a trajectory of evolution of the economy is determined, which has effects on all other systems.

Through feedback mechanisms and processes, the system of the national economy continuously adjusts and adapts in order to reach the potential output. According to (Scarlat \& Chiriţă, 2003), gross domestic product is the representative variable for observing the state of the economy.

The analysis of the global economic system poses new challenges in understanding the behavior of producers and consumers in the market for goods and services, a difficulty enhanced by the phenomenon of globalization, which facilitates the entry into the international market of more and more actors, which is why it must be constantly monitored. Moreover, consumers are encouraged to purchase more and more goods and services, the variety of which is constantly growing. The same consumers, the majority from the household sector, have more opportunities to increase their total income, and thus their disposable income by finding a job in the external sector.

DOI: $10.24818 / 18423264 / 55.1 .21 .02$ 
The Cybernetic System of the Global Economy with Influences of Climate Change on the Evolution of IT

Therefore, at a global scale, the processes of regulating the supply and demand of goods and services, respectively resources and energy, comprises profitable companies that are in search of specialized staff, households willing to maximize their disposable incomes and governments that encourage international trade and pursue local economic growth. Furthermore, the international market is harder to access by the producer sector as existing firms already have experience and consumer preferences are harder to predict.

The third scientific landmark belongs to (van Kooten, 2013) and consists of a general diagram that integrates the system of the global economy, but also the effects of climate change. It serves to shape the global economic system, which takes into account the effects of climate change, and aims to generate scenarios for forecasting the amount of future emissions.

Firstly, (van Kooten, 2013) proposes a system of the global economy, comprising subsystems representative of the energy sector, land use (agriculture, forest area, etc.) and the industrial sector, all of which are directly related to international trade activity.

Demand for energy can arise through transport, heating, electricity or other services, while supply, similarly to energy production, is represented by the sources used: fossil fuels, nuclear, biomass, wind or solar, etc. Renewable, nuclear and fossil fuel sources are treated separately to facilitate the inclusion of technological change parameters. Sometimes electricity is treated separately from the transport and heating system.

The land use sector deals with emissions from agriculture and forestry. Similar to the energy sector, it is based on supply and demand functions: demand is given by the food industry, fuels, wood processing and the services involved, and supply is given by the limited existence of available space for agriculture, livestock farming, afforestation, etc. This sector interacts with the commercial sector for the sale of raw materials and products and for the provision of specific services, and with the energy sector in order to support manufacturing processes.

The commercial sector is based on the supply and demand of goods and services produced by the other two above. Together with trade, it encloses the main elements of the economic system in a model that will generate scenarios for future emissions.

Secondly, there is a climate model, which is defined in a general sense, being at the discretion of each modeler what elements to include (temperature variation, sea level, ice cap surface, amount of precipitation, impact of climate disasters, etc.).

The relations between the economy and the climate model are manifested directly, by providing funds to prevent climate change, but especially indirectly through the emission of greenhouse gases, mainly from industrial sources, plus emissions from land use, waste decomposition, forest area reduction, etc.

In addition to these large complex systems, the general diagram (van Kooten, 2013) proposes a number of key indicators in the evolution of the global

DOI: 10.24818/18423264/55.1.21.02 
economy and community: gross domestic product, population, technological factors and available natural resources. They directly influence the state of the economy through the goods and services market, the labor market and they can be affected by the climate module. Moreover, the issue of the availability of natural resources also brings up the progress of technology: it can accelerate the reduction of resources available in case of irresponsible use, but it can also make huge contributions in terms of sustainability and prevention of the effects of climate change.

The interactions described above can be captured within the overall model of the global economy and climate by means of variables, which act like weights and can be adjusted, generating several scenarios that can be compared in terms of the effects that propagate in the system.

Finally, the fourth scientific benchmark is the DICE model (Wang Z., 2017), which integrates a general model of equilibrium of the world economy and a climate system, plus greenhouse gas emissions, carbon dioxide concentration, climate change, their impact and optimal policy. Moreover, DICE is an integrated evaluation model that aims to find the optimal policy, considering that the saving and investment behaviors are based on Ramsey's model. The world is seen as a whole, so countries and regions are not differentiated. DICE focuses on the quantitative impact of climate change on the economy and on the analysis of gains and losses in the world economy, which is due to the implementation of a climate protection policy.

From an analytical perspective, the DICE model provides for the introduction of an objective function representing the maximization of social wellbeing (Wang Z., 2017). The model then incorporates elements that characterize the complex system of the global economy with the influences of climate change by considering the following systems: economic, geophysical and climatic, the latter being represented by the carbon cycles that result in the industrial emissions and the emissions from the atmosphere, the use of land, oceans and vegetation.

\section{General Model of the Economy and Climate Change}

A general model of the global economy that integrates the effects of climate change is characterized by complex feedback processes, the outcome of which is difficult to predict. Besides, in its construction are trained a multitude of variables, dependencies, limits and parameters, which correspond to hypotheses and beliefs adopted by the modeler.

We note that consumption function, GDP, global capital, the impact of climate disasters, the accumulation of emissions and the increase in global temperature are the main variables to which other variables converge, such as global population, net production or increased solar radiation. There are multiple independences between them that hinders the prediction of a result.

DOI: $10.24818 / 18423264 / 55.1 .21 .02$ 
The Cybernetic System of the Global Economy with Influences of Climate Change on the Evolution of IT

The economic and geophysical system are connected by a relation between the total amount of carbon emissions, influenced by production activities and emission control policies, and the change in temperature levels.

Further, the temperature is influenced by the intensity of solar radiation, which belongs to the geophysical system. Then, the geophysical system also interacts with the climate system, the one that comprises the cycles of atmospheric carbon, the one in the oceans and from vegetation. The relations between them are based on the influence of carbon emissions on global temperature, indirectly, by contributing to the total amount of carbon emissions marked in the Accumulating emissions.

To begin with, the economic system encompasses several subsystems, also called modules, which are interdependent and communicate with the geophysical and climatic systems, the latter being represented by the carbon cycles (atmospheric, land use, vegetation, etc.). Thus, the economic system comprises: the social welfare module, including the consumption function, the productivity of technological factors system, the global capital circulation system, the global population system, the climate - oriented costs module which takes into account the impact of climate disasters, global GDP as a stand - alone variable and the module for the emission accumulation process. The economic system links to the other two systems as follows: (1) with the geophysical system through the global average temperature, a variable belonging to it, being directly influenced by the amount of carbon emissions, around which the DICE model is also oriented; (2) with the system incorporating carbon cycles through the process of accumulating emissions from several sources (industrial, land - use, atmospheric, oceans, vegetation).

Clearly, the current population is defined as the difference between the number of people born from which the number of deceased is subtracted, taking into account the mean birth rate and mortality rate. The evolution of population influences the economy through changes in consumption trends and tax levels, becoming necessary to closely monitor the generations.

The productivity of technological factors is directly linked to innovation and the processing power of computers. However, the trend of increasing technological innovation is expected to continue, but the value of the pace will gradually decrease as a result of the technological boom. There will certainly be others that will challenge industries to evolve to a higher level. The productivity aspect of inputs directly influences net output globally and, indirectly, the consumption function of the population and the level of investment, implicitly the global capital. In turn, global capital determines the level of production in the next period.

Global capital consists in all goods and services that circulate in the global economic system, thus more than the existing monetary mass in banks. This capital increases with investments, which are influenced by the saving rate of the population, and depreciates with a certain depreciation rate. Investment is

DOI: 10.24818/18423264/55.1.21.02 
Delia Bălăcian, Emil Scarlat

influenced by the effects of climate change, taking into account the impact of climate disasters, detailed below.

The use of the world GDP in this module is justified by its powerful influence on climate evolution from the point of view that it represents the global economic output, being the result of the interaction between population and existing capital. It has direct effects on climate disasters, which are costs associated with overall temperature increases.

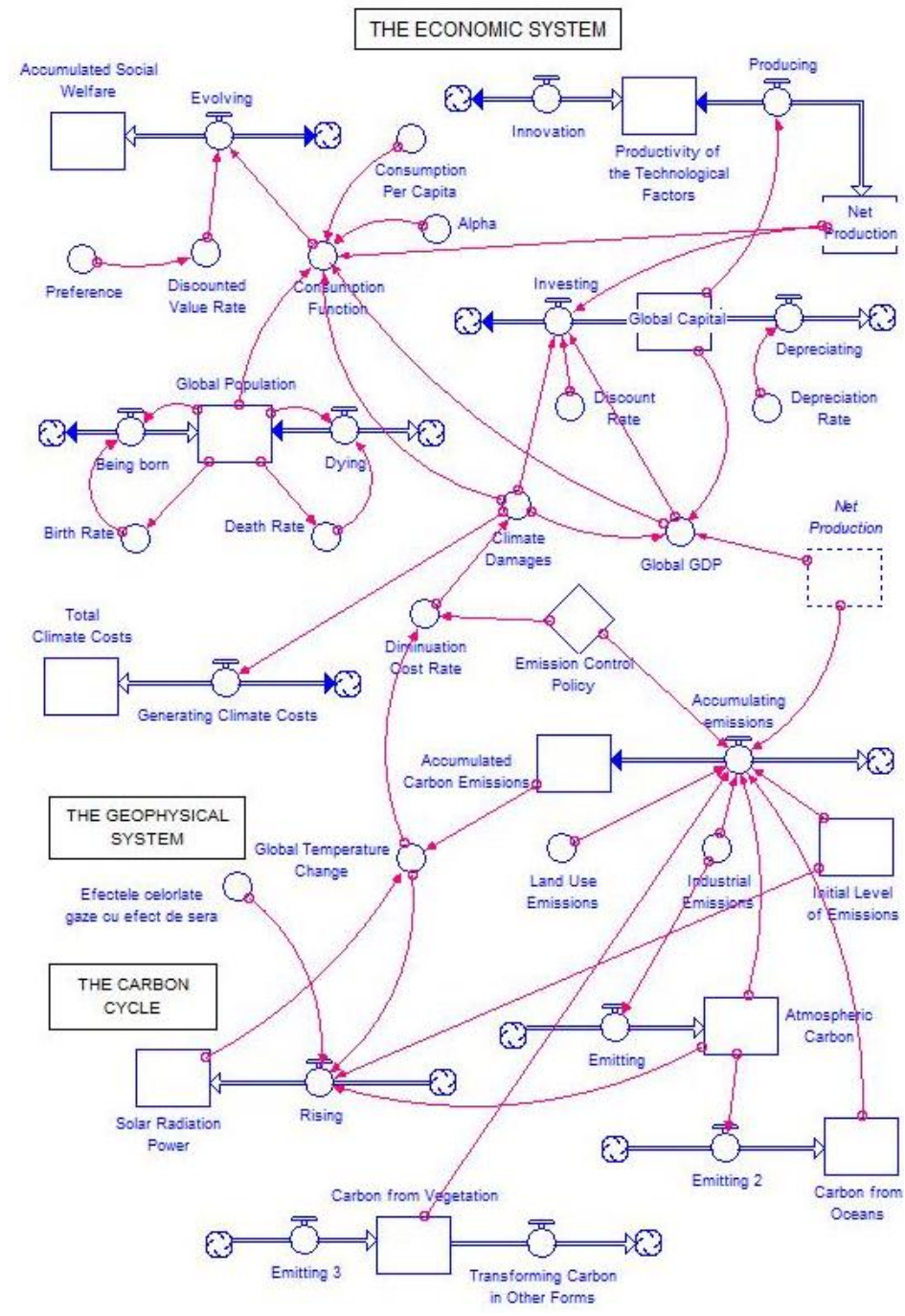

Figure 1.The General Model of the Global Economy with Influences of Climate Change

DOI: $10.24818 / 18423264 / 55.1 .21 .02$ 
The Cybernetic System of the Global Economy with Influences of Climate Change on the Evolution of IT

The impact of climate disasters is estimated in monetary units and represents the costs generated by extreme events, the implementation of tougher fiscal policies such as environmental permits, the redirect of funds to urgent climate problems or the mitigation of the effects of climate change. Of course, there can be other types of similar costs, the choice belonging to the modeler.

In building a model that captures the relations between the economy and the climate, an absolutely necessary aspect to be considered refers to the feedback loops. Climate feedback loops are " processes that can either amplify or diminish the effects of climate forcings." "Forcings" here are the initial drivers of our climate - things like solar irradiance, GHG emissions, and airborne particles like dust, smoke, and soot that come from both human and natural sources and impact our climate), (The Climate Reality Project, 2020). Therefore, feedback loops change the impact of key factors, causing a chain reaction.

The water vapors cycle is a suitable example in this case: the more greenhouse gases are emitted, the warmer the atmosphere gets; the resulting warm air causes more water being evaporated from oceans, rivers, lakes and soil, sending even more vapors into the atmosphere; water vapors retain heat, so excess vapors amplify the initial heat; more heat leads to a more intense evaporation process, resuming the cycle again and again.

Given this vicious cycle, positive feedback loops are prone to getting out of control, possibly causing irreversible changes to the climate system. For this reason, increased attention should be paid to negative feedback loops, which have a stabilizing effect on these changes.

According to the National Oceanic and Atmospheric Administration (NOAA), "The accelerating effects of positive feedback loops can be at risk to irreversible tipping points, which are changes to the climate that are not steady and predictable. Basically, tipping points are small changes within the climate system that can change a fairly stable system to a very different state. Similar to a wine glass tipping over, wine is spilt from the glass as the tipping event occurs and standing up the glass will not put the wine back; the state of a full wine glass becomes a new state of an empty glass" (The Climate Reality Project, 2020). Such small, but cumulative changes that trigger irreversible changes also happen in the climate system (melting of the ice cap, the rise of ocean and sea water levels, etc.). From this point of view, particular attention should be paid to the relations and the feedback processes between the variables of the model.

\section{Proposed Models for Integrating in the General Model}

The overall model comprises the main activities of an open economy, placed in the context of climate change, but other models can be added by observing the dependencies between the economy and the climate at a more detailed level. 
Delia Bălăcian, Emil Scarlat

\subsection{The Model of Price Formation on the Goods and Services Market}

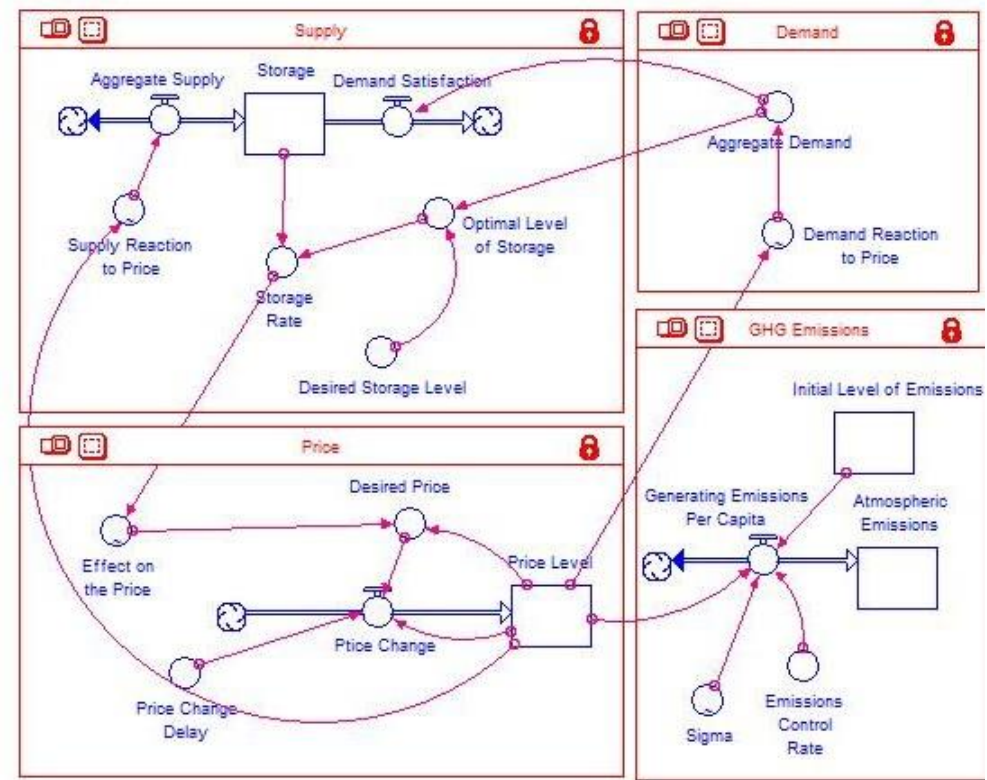

Figure 2. The Model of Supply and Demand with Price and Storage Formation

Price influences the level of growth by its value. In the case of a high price, consumers are limited by the financial possibility they may or may not have for the purchase of the good or service in question. In the case of a small price, the consumer's choice shall be subject to his preference.

Regarding the aggregate supply, there are two possibilities, depending on the level of storage. If the existing stock is lower than the optimal storage level, then demand is higher than supply and short-term production is encouraged: short - term storage growth leads to higher costs, which will lead to an increase in the price level. On the other hand, if the existing stock is above the optimal level, then the price decreases because the supply exceeds the demand.

The amount of greenhouse gas emissions is directly influenced by production rather than the market price. Indirectly, if consumers are willing to pay higher prices without imposing an environmental responsibility on producers, then everything remains the same. A legislative measure is needed to determine producers to have a greater environmental responsibility. We can capture the effectiveness of environmental policy implementation by introducing a parameter that adjusts the amount of emissions generated according to the desired scenario. The input flow of the Atmospheric Emissions Level variable follows the relationship:

$$
\begin{aligned}
\text { Atmospheric Emissions }= & \sigma *(1-E C R) * \text { Price Level }+ \\
& \text { Initial Level of Emissions }
\end{aligned}
$$

DOI: $10.24818 / 18423264 / 55.1 .21 .02$ 
The Cybernetic System of the Global Economy with Influences of Climate Change on the Evolution of IT

The parameter $\sigma$ (sigma) stands for the ratio of emissions generated per dollar from the value of GDP. Then, the emission control rate takes values between 0 and 1 , where zero means that the policy adopted is one that does nothing to reduce emissions and one signifies the adoption of a policy in which emission reduction efforts are maximum. It should be noted that in the latter case $(\mathrm{ECR}=1)$ the result of the above equation is null, meaning there would be no harmful emissions at all, not even those from the burning of fossil fuels (The Pennsylvania State University, 2020). This is a parameter that lends itself to modeling as a growing function, assuming that over time, governments will be more inclined towards adopting more responsible and stricter policies towards climate change.

\subsection{The Model of Population Evolution}

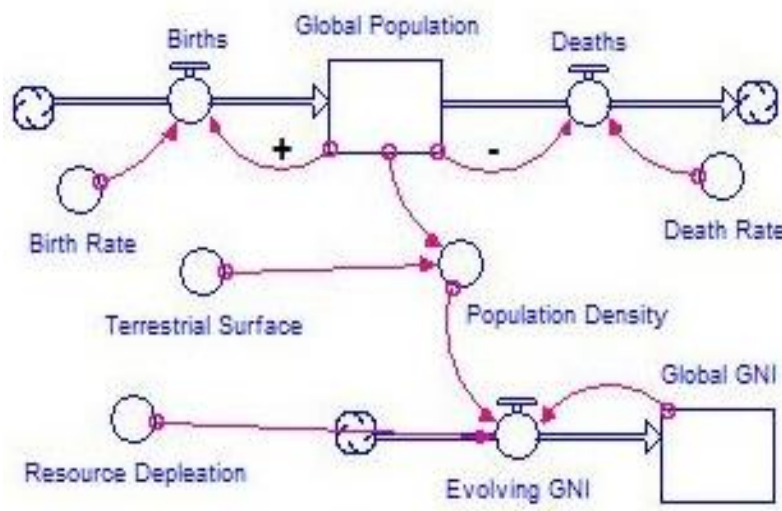

Figure 3. The Model of Population Evolution

In the analysis of the dependencies between the global economy and climate changes, the evolution of population stands out as a common feedback mechanism, which is influenced by the changes in the economy and/or climate, but also enhances them at a certain level. There is a theory that the Earth's capacity to sustain population is around 9 to 10 billion people, limited due to the availability of natural resources such as water, the area of arable land, the area needed to raise animals and birds, and so on.

The model discussed in this part of the chapter aims to forecast the level of the future population, based on historical and current data of the indicators. Population is an essential element in the context of climate change, namely the growth rate of earth's inhabitants. The level equation used to determine the future population is:

$$
\text { Population }_{t+1}=\text { Population }_{t} *(\text { Birth Rate }- \text { Death Rate })
$$

DOI: 10.24818/18423264/55.1.21.02 
Delia Bălăcian, Emil Scarlat

\subsection{The Model of Energy Consumption}

The energy sector is the main contributor to the accumulation of greenhouse gas emissions. Energy "leads" the world, meaning that it warms our homes, mediates our food preparation, brightens our evenings, feeds our transports, provides our communications and access to the digital world, etc. Of course, energy costs are linked to each country's economy: high costs slow economic growth, and low costs allow for accelerating economic growth. Then comes the strategic potential of energy. It is important that a country's energy sources are well secured, as an energy disruption has negative effects both internally, practically "closing" the activity of the country concerned and externally, influencing political treaties between countries or foreign investments. However, the use of energy also has consequences. Environmental changes, generated by energy exploitation, affect everyone's lives. Climate change is only part of the environmental problem, and pollution is sometimes more important.

Therefore, below is a system in which the evolution of population influences energy consumption in general. Population consumption is not differentiated according to the resource consumed (oil, natural gas, electricity), but is considered globally, and the parameters of the initial energy consumption level and the consumption rate can be changed according to the analyzed resource.

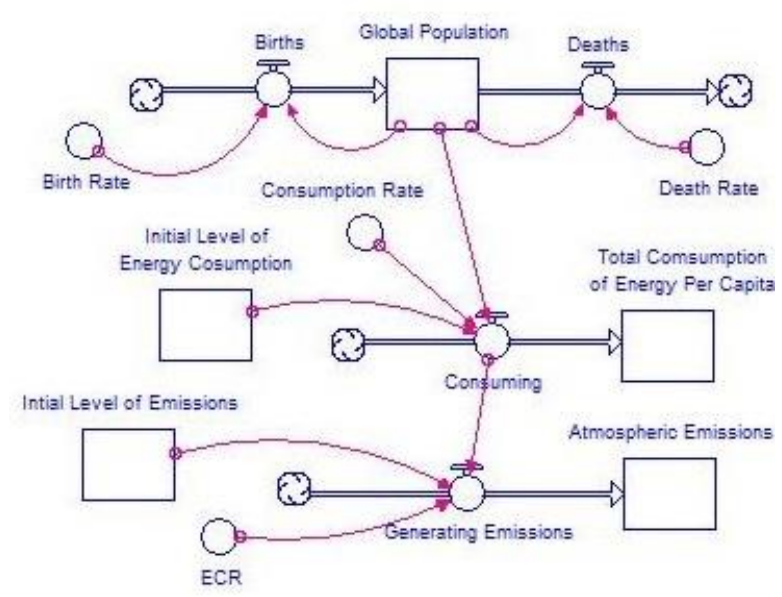

Figure 4. The Model of Energy Consumption

The aim of the model is to observe the trend of the amount of harmful emissions when the level of public administration involvement changes, i.e. when the ECR, discussed above, has a higher value, leading to a decrease in the amount of emissions generated. The reaction to the change in the population's consumption rate is also analyzed, as the population is expected to maintain its upward trend, but with a decreasing growth rate.

DOI: 10.24818/18423264/55.1.21.02 
The Cybernetic System of the Global Economy with Influences of Climate Change on the Evolution of IT

The energy consumption rate of the population, as well as the type of energy it encourages, have direct effects on climate change by generating greenhouse gas emissions, especially carbon dioxide emissions.

The model comprises a rate of energy consumption, calculated in relation to the population at the time. It does not take into account different forms of energy production, but can be developed in this direction by gathering more specific information on the possibilities of generating greenhouse gas emissions. For example, France mostly uses low - emission nuclear energy, as opposed to burning fossil fuels, widely used in China or the United States, which is a major contributor to the amount of greenhouse gas emissions: $31 \%$ of the global consumption of fossil fuels are attributed to the Chinese population. Therefore, a rate of energy consumption is given according to the level of population and global consumption. This value can be given as input for the model, based on the analysis of historical data of countries (World Resources Institute, 2019).

Further, the input flow value through which the consumption function is represented results from the multiplication of a given starting value (average consumption based on historical data from the last decades, a specific consumption from a reference year for the whole model, etc.) and the energy consumption rate. It has a directly proportional relation to the accumulation of greenhouse gas emissions. The input data in the model are indicative.

The process of accumulation of emissions involves both the production and consumption of energy from fossil fuels (majorities), but also the reaction of population to the manifestation of the effects of climate change. The latter is captured in the model with the ECR parameter, i.e. the emission control rate, also used in previous models, with the following relationship:

$$
\begin{aligned}
\text { Atmospheric Emissions }= & (1-E C R) * \text { Generating Emissions }+ \\
& \text { Initial Level of Emissions }
\end{aligned}
$$

\section{Simulation Results}

This section presents the results of the simulations carried out on previous models, with observations on how the flows involved influence their achievement.

\subsection{The Model of Price Formation on the Goods and Services Market}

The graph in Figure 5 illustrates the effects of short - term production in the economy due to very high demand. Stocks, representative of the aggregate market offer, react to the price change according to the classical macroeconomic theory: each additional unit is more difficult or more expensive to produce than the previous one and thus imposes a higher price to justify its production. In other words, the higher the production, the higher the price until demand is met and after the price starts to fall. Because of the gap between the moment when demand is met and the one when the producer is sure of this, stocks accumulate. With the

DOI: 10.24818/18423264/55.1.21.02 
accumulation of stocks, additional storage costs are formed which must be covered by the sale of the products.
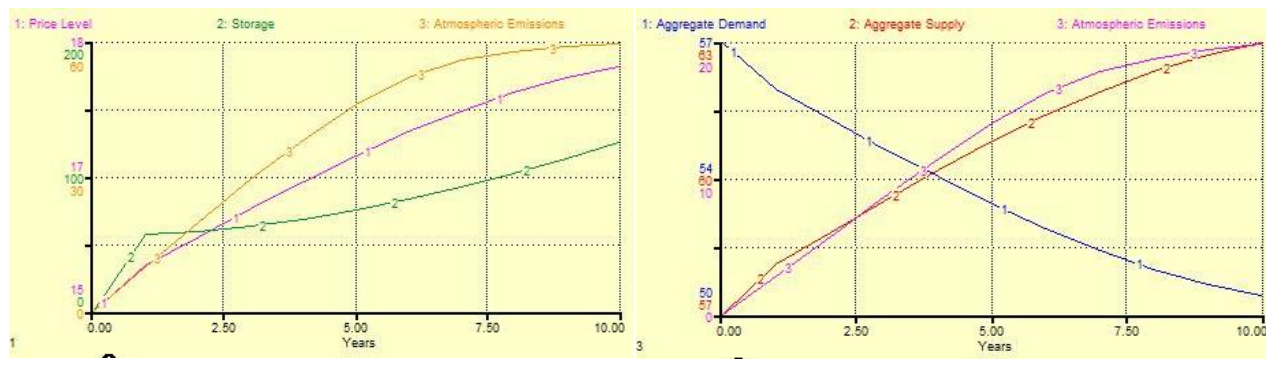

Figure 5. The Evolution of GHG Emissions Considering the Evolution of Price and Stocks (left) and the Equilibrium between Aggregate Demand and Aggregate Supply (right)

In the first two years, stocks are higher than the price, which leads to a slight increase in price due to accumulated stocks, after which we look at the scenario in which the continuous increase in stocks from the moment 1 further, supports the increase in prices.

\subsection{The Model of Population Evolution}

Under this mechanism, we can make predictions for the next 10, 20 or any number of years we consider relevant in our analysis, based on the most recently available data. In this case, 2018 is the most recent year providing population data, with a value of 7,503,828,000 people. Also, we set the 2018 values for the birth rate at $0.018 \%$ and for the mortality rate at $0.007 \%$ (World Bank, 2018). According to the model, the population is expected to be $8,371,329,313$ people in 2028 , and if we keep the same rates, the population would reach 9-10 billion people between 2035 and 2052.

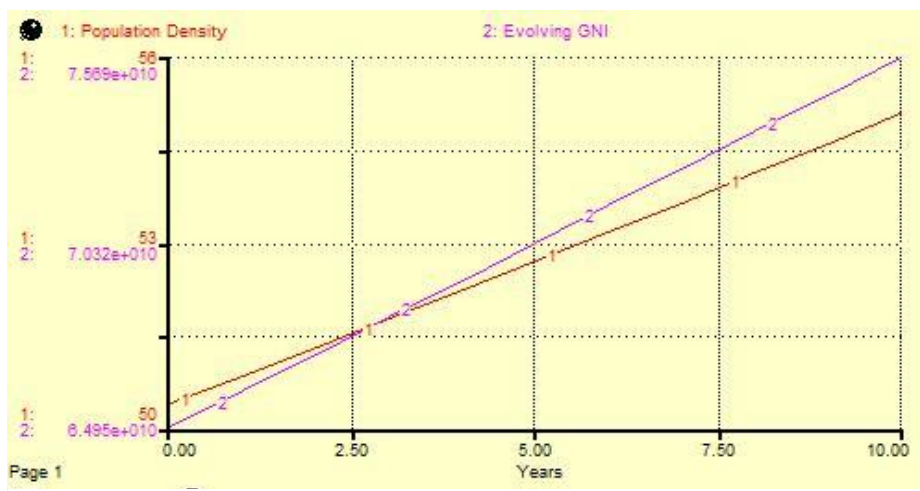

Figure 6. The Evolution of Population Density in Relation with Global GNI 
The Cybernetic System of the Global Economy with Influences of Climate Change on the Evolution of IT

Furthermore, population density is also calculated to highlight public administration issues such as the need to supplement public transport or waste collection points and manage existing resources. The Earth's surface refers to the $29 \%$ of the Earth's total surface area, i.e. 148,940,000 km² (Pidwirny, 2006). Additionally, the decrease in natural resources belonging to a country is observed through gross national income (GNI), expressed in current international dollars per capita per $\mathrm{km}^{2}$. Gross national income totals up to $\$ 128$ trillion in 2018 , and the decline rate of natural resources is $1.288 \%$ of GNI annually (World Bank, 2018). To ensure the correspondence of units of measure, this value will relate to population density at the given time.

Over the next 8 years, meaning by 2026, population density is expected to increase by four people per $\mathrm{km}^{2}$, thus respecting the increasing trend of the evolution of national income, and also the consumption of natural resources.

\subsection{The Model of Energy Consumption}

Obviously, an increase in the emission control rate, i.e. the imposition of stricter and more efficient environmental policies, will lead to a significant decrease in the accumulated emissions. If we look at the extreme point, where policies are very strict, the disadvantages of this measure are felt in the social plan because tougher measures diminish the usual comfort of people and, more importantly, inhibit business development since there will be more instruments to penalize any deviation from compliance with the central administrative plan. On the other hand, an increase in the energy consumption rate in general is expected to lead to a significant increase in the amount of emissions as the energy sector is responsible for $70 \%$ of carbon dioxide emissions.
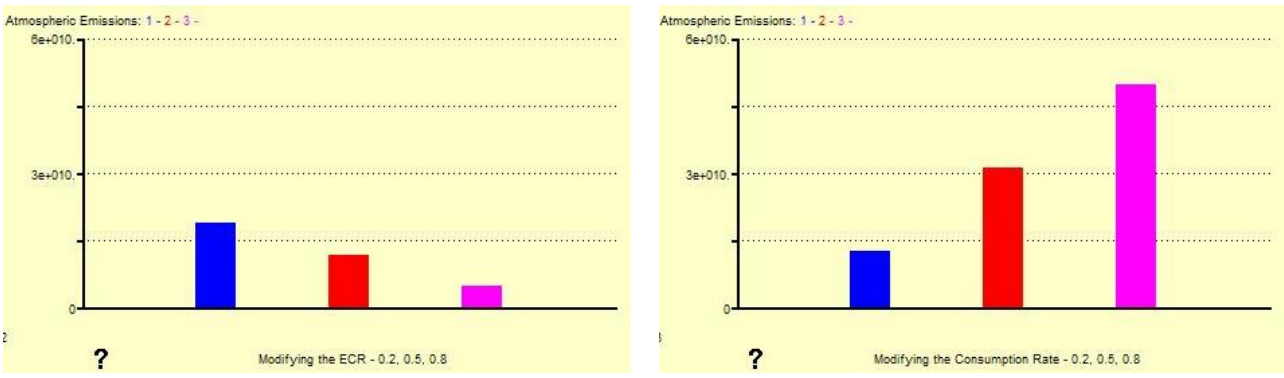

Figure 7. The Trend of Atmospheric Emissions when Modifying the Emission Control Rate (left) and the Consumption Rate (right)

If we look at the graphs in Figure 7 in terms of proportions, we note that an energy consumption rate of equal weighting to the emission control rate causes a greater decrease in the amount of emissions generated. 


\section{Conclusions}

To begin with, we recall the importance of feedback loops within any system: a negative feedback loop is a process that causes a stabilization in the operation of the model, while a positive feedback loop accelerates the system's "response" to that change. Therefore, their effects counterbalance and lead the system to a state of equilibrium.

Firstly, we conclude that there are more positive feedback loops, with an accelerating impact on the effects of the system, than negative feedback loops, with the role of balancing and adjusting flows in accordance with the system objective. The proposed models for observing the detailed relations between the global economy and the climate change were discussed: the ways in which price influences supply and demand and, indirectly, emissions from productive activity, the relationship between the Earth's population and available natural resources and, finally, the links between the energy sector, the population and the amount of emissions.

Secondly, according to the model, the population is expected to be $8,371,329,313$ people in 2028 , and if we keep the 2018 birth and mortality rates, the population would reach the maximum estimated level for sustainability of 9-10 billion people between 2035 and 2052. This growth encourages increased consumption of goods and services and also energy, then production and energy sectors generate industrial emissions.

Thirdly, in the process of building the model, several obstacles arise, which relate to the perspective of the modeler on the variables, on their limits or on the integrations of them within the system. The same structure can have several results if we modify constant variables, viewed as parameters, such as the emission control rate, and a result or scenario can be achieved through multiple combinations of flows and stocks.

System dynamics is a method that gives the modeler the ability to try many scenarios and model architectures that, although they work differently, pursue the same goal. Therefore, the future of this type of analysis of complex systems of the global economy in relation to climate change is open to various future developments such as:

- detailing the effects of climate change by including a variable for temperature variation or flows and stocks for each of the main greenhouse gases (carbon dioxide, methane, nitrogen dioxide and others);

- integrating the individual systems presented in this paper into one that tracks the link between consumer choices and the effects of climate change;

- defining a complex system of the global economy, highlighting the main processes and feedback mechanisms contained therein.

Of course, there are many other options to consider. We believe that the potential of this work is significant and can be developed in the future in convergent directions, with the common objective of supporting decision-makers

DOI: $10.24818 / 18423264 / 55.1 .21 .02$ 
The Cybernetic System of the Global Economy with Influences of Climate Change on the Evolution of IT

in the process of setting economic and environmental policies. Moreover, this work can be useful for informing the general public and we think it manages to highlight the importance of our present actions for the future of our world.

Finally, there are numerous studies, analyses, research carried out in this area that can help decision-makers in leading the necessary change within each company. However, two main issues remain: the lack of information for people on this subject and, more importantly, the need for a clear and determined direction for world leaders addressing climate change.

\section{REFERENCES}

[1] Beyene, S. \& Kotosz, B. (2019), Taylor\&Francis Online. Online: https://www.tandfonline.com/doi/full/10.1080/00207233.2019.1695445?scroll $=$ top \&needAccess=true, [Accessed 30.04.2020];

[2] Pidwirny, M. (2006), Surface Area of Our Planet Covered by Oceans and Continents. (Table 8o-1). University of British Columbia, Okanagan. Online:http://www.physicalgeography.net/fundamentals/8o.html, [Accessed 30.05.2020];

[3] Rosa E. A., Rudel T. K., York R., Jorgenson A. K., Dietz T. (2015), The Human (Anthropogenic) Driving Forces of Global Climate Change. Climate Change and Society - Sociological Perspectives, 32-53. New York, United Stated of America: Oxford University Press;

[4] Scarlat, E. \& Chiriță, N. (2003), Cibernetica sistemelor economice. Bucharest: ASE Publishing;

[5] Stern, D. I. (2004), The Rise and Fall of the Environmental Kuznets Curve. World Development, 32:1419 - 1439;

[6] The Climate Reality Project (2020), How Feedback Loops Are Making the Climate Crisis Worse. Online: https://climaterealityproject.org/blog/howfeedback-loops-are-making-climate-crisis-worse, [Accessed 17.02.2020];

[7] The Pennsylvania State University (2020), DICE Model Background.. Online:https://personal.ems.psu.edu/ dmb53/Earth_System_Models/DICE_Ba ckground.html, [Accessed 20.03.2020];

[8] Tol, R. S. J. (2019), Climate Economics. United Kingdom: Edward Elgar Publishing Limited.

[9] Van Kooten, G. (2013), Climate Change, Climate Science and Economics Prospects for an Alternative Energy Future. Canada: Springer;

[10] Wang Z., Liu C., Wu J., Gu G. (2017), Integrated Assessment Models of Climate Change Economics. Singapore: Springer Nature;

[11] World Bank, Birth Rate, Gross (per 1000 persons). Online: https://data.worldbank.org/indicator/SP.DYN.CBRT.IN?locations=1W\&name _desc=false\&vvie=chart, [Accessed 25.03.2020];

DOI: $10.24818 / 18423264 / 55.1 .21 .02$ 
Delia Bălăcian, Emil Scarlat

[12] World Bank, GNI, PPP (current international \$). Online: https://data.worldbank.org/indicator/NY.GNP.MKTP.PP.CD, [Accessed 30.05.2020];

[13] World Bank, Mortality Rate, Gross (per 1000 people). Online: https://data.worldbank.org/indicator/SP.DYN.CDRT.IN?locations=1W\&name desc $=$ false \& view $=$ chart, [Accessed 25.03.2020];

[14] World Resources Institute (2019), Which Countries Use the Most Fossil Fuels. Online: https://cleantechnica.com/2019/05/03/which-countries-use-themost-fossil-fuels/, [Accessed 09.04.2020]. 